OPEN ACCESS

Edited by:

Lei-Miao Yin,

Shanghai University of Traditional

Chinese Medicine, China

Reviewed by:

Susanna Carola Fagerholm

University of Helsinki, Finland

Ben Goult,

University of Kent, United Kingdom Jon Humphries,

The University of Manchester. United Kingdom

Massimiliano Baldassarre, University of Aberdeen United Kingdom

${ }^{*}$ Correspondence: Isabelle Lamsoul Isabelle.Lamsoul@inserm.fr

Pierre G. Lutz

Pierre.Lutz@inserm.fr

Specialty section:

This article was submitted to Cell Adhesion and Migration, a section of the journa Frontiers in Cell and Developmental Biology

Received: 04 August 2020 Accepted: 05 November 2020 Published: 20 November 2020

Citation:

Lamsoul I, Dupré L and Lutz PG (2020) Molecular Tuning of Filamin A Activities in the Context of Adhesion and Migration.

Front. Cell Dev. Biol. 8:591323. doi: 10.3389/fcell.2020.591323

\section{Molecular Tuning of Filamin A Activities in the Context of Adhesion and Migration}

\author{
Isabelle Lamsoul ${ }^{1 *}$, Loïc Dupré1,2 and Pierre G. Lutz ${ }^{1 *}$ \\ ${ }^{1}$ Centre de Physiopathologie de Toulouse Purpan, INSERM, CNRS, Université de Toulouse, UPS, Toulouse, France, \\ ${ }^{2}$ Ludwig Boltzmann Institute for Rare and Undiagnosed Diseases, Vienna, Austria
}

The dynamic organization of actin cytoskeleton meshworks relies on multiple actinbinding proteins endowed with distinct actin-remodeling activities. Filamin $A$ is a large multi-domain scaffolding protein that cross-links actin filaments with orthogonal orientation in response to various stimuli. As such it plays key roles in the modulation of cell shape, cell motility, and differentiation throughout development and adult life. The essentiality and complexity of Filamin $A$ is highlighted by mutations that lead to a variety of severe human disorders affecting multiple organs. One of the most conserved activity of Filamin $A$ is to bridge the actin cytoskeleton to integrins, thereby maintaining the later in an inactive state. We here review the numerous mechanisms cells have developed to adjust Filamin A content and activity and focus on the function of Filamin A as a gatekeeper to integrin activation and associated adhesion and motility.

Keywords: actin cytoskeleton, filamin, integrin, cell adhesion, cell migration

\section{INTRODUCTION}

The filamin protein family is represented in nearly all Metazoa. Phylogenetically, the filamin genes diverge from a common single ancestral gene between chordate invertebrate and vertebrate lineages. Filamins comprise a N-terminal actin-binding domain (ABD) composed of two actinbinding calponin homology $(\mathrm{CH})$ domains followed by immunoglobulin like repeats (IgFLN) of high sequence similarity (van der Flier and Sonnenberg, 2001). All C-terminal filamin repeats of filamins characterized so far have the property to homodimerize. The number of filamin repeats differs substantially in invertebrates but is almost constant in vertebrates (Light et al., 2012). The vertebrate genomes contain three filamins, Filamin A, B and C, with an intraspecies sequence identity of over $64 \%$ (Kesner et al., 2010). Filamins A and B are ubiquitously expressed, whereas Filamin $C$ is expressed in smooth and striated muscles. Filamins A and B are localized to the cortex and stress fibers, whereas Filamin $\mathrm{C}$ is localized to the sarcomeric Z-line complex (van der Ven et al., 2000; Sheen et al., 2002). Disease-associated mutations and knockout mouse models suggest that Filamins A and B are critical for various aspects of skeletal, vasculature, cardio, and cerebral development (Fox et al., 1998; Sheen et al., 2002; Robertson et al., 2003; Krakow et al., 2004; Farrington-Rock et al., 2006, 2008; Feng et al., 2006; Hart et al., 2006; Lu et al., 2007; Zhou et al., 2007; Metais et al., 2018; Yamak et al., 2020), whereas Filamin C is essential for skeletal muscle and heart development (Goetsch et al., 2005; Vorgerd et al., 2005; Dalkilic et al., 2006; Duff et al., 2011; Zhou et al., 2020). 


\section{FILAMIN A, A HUB FOR MULTIPLE BINDING PARTNERS}

Filamin A interacts with about a hundred binding-partners, many of which being involved in the regulation of signaling pathways converging toward actin cytoskeleton organization (Figure 1). Filamin A has a dual role in controlling the architecture and the mechanics of the actin cytoskeleton. Filamin A is an actinbinding and cross-linking protein whose primary function is to organize the actin cytoskeleton in orthogonal filament arrays (Nakamura et al., 2007). Importantly, the mechanic properties of this filamentous actin (F-actin) network is dependent on Filamin A concentration (Tseng et al., 2004; Gardel et al., 2006; Esue et al., 2009). At high Filamin A concentration, tighter F-actin bundles are observed and the F-actin network undergoes stress stiffening under applied forces (Schmoller et al., 2009). In contrast, at lower relative Filamin A cross-link concentrations, the F-actin cytoskeleton is more dynamic and can soften in response to stress (Tseng et al., 2004). Furthermore, the non-linear elasticity of the actin network is attributed to the flexibility of Filamin A (Kasza et al., 2009; Schmoller et al., 2009). Filamin A also localizes to points of intersection between stress fibers and cortical actin where it plays a role in the isotropic redistribution of applied forces to focal adhesions (Kumar et al., 2019). Three actinbinding sites (ABS) within the Filamin A ABD were recently identified (Figure 1; Iwamoto et al., 2018). The first one, ABS$\mathrm{N}$, located at the $\mathrm{N}$-ter of the $\mathrm{CH}$ domain 1 contributes to $\mathrm{F}$-actin binding while the two others, ABS2 and ABS2', facilitate binding in the groove between adjacent actin subunits (Iwamoto et al., 2018). While the ABD is necessary and sufficient for F-actin binding (Razinia et al., 2011), a domain within a Filamin A fragment encompassing filamin repeats 9 to 15 is necessary for high avidity F-actin binding (Nakamura et al., 2007).

In mammals, the ABD of filamins is followed by 24 filamin repeats interrupted by two hinge regions often referred as rod 1 and 2, one between repeats 15 and 16 and another between repeats 23 and 24 (Figure 1). Filamin $\mathrm{A}$ domains can be divided into four subgroups (A, B, C, and D) based on amino acid similarities (Ithychanda et al., 2009b). Filamin A repeats of subgroup A (4, 9, 12, 17, 19, 21, and 23) interact with a set of biologically important ligands including platelet receptor glycoprotein Ib $\alpha$ (GPIb $\alpha$ ) (Nakamura et al., 2006), migfilin (Lad et al., 2008; Ithychanda et al., 2009a,b), Cystic Fibrosis Transmembrane conductance Receptor (CFTR) (Smith et al., 2010), FilGAP (Nakamura et al., 2009), Pro-prion (Li et al., 2010), Ankyrin repeat containing protein with a SOCS box 2 alpha (ASB2 $\alpha$ ) (Lamsoul et al., 2011) and $\beta$ chains of integrins (Kiema et al., 2006; Takala et al., 2008). All subgroup A Filamin A repeats and their binding partners have similar mode of interaction. Indeed, the CD face of Filamin A repeats represents a common interface for Filamin A-ligand interaction (Lad et al., 2007; Heikkinen et al., 2009). Interestingly, Filamin A repeats can also engage in intramolecular contacts (IgFLNa16-17, IgFLNa18-19, and IgFLNa20-21) that may become disrupted by binding of one of the repeats to the integrin $\beta$ cytoplasmic tail or by mechanical forces (Lad et al., 2007; Heikkinen et al., 2009). Smoothelins A and $\mathrm{B}$, as well as fimbacin can bind to the cryptic CD cleft of Filamin A repeat 21 exposed in mechanically activated Filamin A (Wang and Nakamura, 2019a,b). Filamin A can also interact with small GTPases of the Rho family, Rac, Rho, cdc42, and RalA (Ohta et al., 1999; Bellanger et al., 2000; Vadlamudi et al., 2002; Ueda et al., 2003) and with proteins upstream and downstream of the GTPases (Ohta et al., 2006; Nakamura et al., 2009) known to regulate cytoskeletal dynamics and cell protrusions. In addition, RhoA activity is downregulated through interactions between Filamin $A$ and $\alpha \operatorname{IIb} \beta 3$ integrins and is critical to proplatelet formation (Donada et al., 2019).

Filamin A is also localized into the nucleus where it plays roles in DNA repair through interaction with BRCA1 and BRCA2 (Yue et al., 2009; Velkova et al., 2010), as well as transcription through interaction with transcription factors such as the androgen receptor (Loy et al., 2003; McGrath et al., 2013; Savoy et al., 2015), Smads (Sasaki et al., 2001) or PEBP2 $\beta / C B F \beta$ (Yoshida et al., 2005). Filamin A also associates with the MKL1 transcriptional co-activator, stimulating the activity of the Serum Responsive Factor (SRF) transcription factor and cell migration (Kircher et al., 2015).

How Filamin A integrates the signals triggered by its multiple binding partners and whether such complex molecular interactions might be tuned differentially in different cell types remain key open questions. Nevertheless, the essentiality of Filamin A is highlighted by variants in the gene FLNA that lead to 10 distinct genetic syndromes affecting a wide diversity of organs (Wade et al., 2020). Importantly, pathogenic variants of FLNA could contribute to aberrant cytoskeletal regulation leading either to loss-of-function or gain-of function disorders. Indeed, variants are found in the two $\mathrm{CH}$ domains of the $\mathrm{ABD}$, CHD1 and 2, in periventricular nodular heterotopia $(\mathrm{PH})$ and otopalatodigital (OPD) syndromes type 1 and 2, respectively. Variants within CHD1 are likely to disrupt Filamin A interaction with actin (Iwamoto et al., 2018) whereas variants within CHD2 are likely to constitutively expose the CHD1 ABS to ligand (Clark et al., 2009). Interestingly, a mutation in FLNA in a male patient with $\mathrm{PH}$ and congenital intestinal pseudoobstruction potentiates $\alpha \operatorname{IIb} \beta 3$ integrin activation likely through less binding of mutant Filamin $A$ to $\beta 3$ integrin and facilitated recruitment of Talin by the $\beta 3$ subunit (Berrou et al., 2017). The relationship between other FLNA pathogenic variants and Filamin A functions is less understood and remains to be investigated.

\section{FILAMIN A, A NEGATIVE REGULATOR OF INTEGRINS}

Because the filamin domains involved in binding actin and integrins have the highest content of ancestral residues of any domains (Kesner et al., 2010), integrins are considered among the most important interaction partners of filamins. Integrins are heterodimeric transmembrane receptors formed by $\alpha$ and $\beta$ subunits. These are single spanning membrane proteins with a large extracellular ectodomain and a short intracellular cytoplasmic tail. Integrins mediate cell to extracellular matrix 


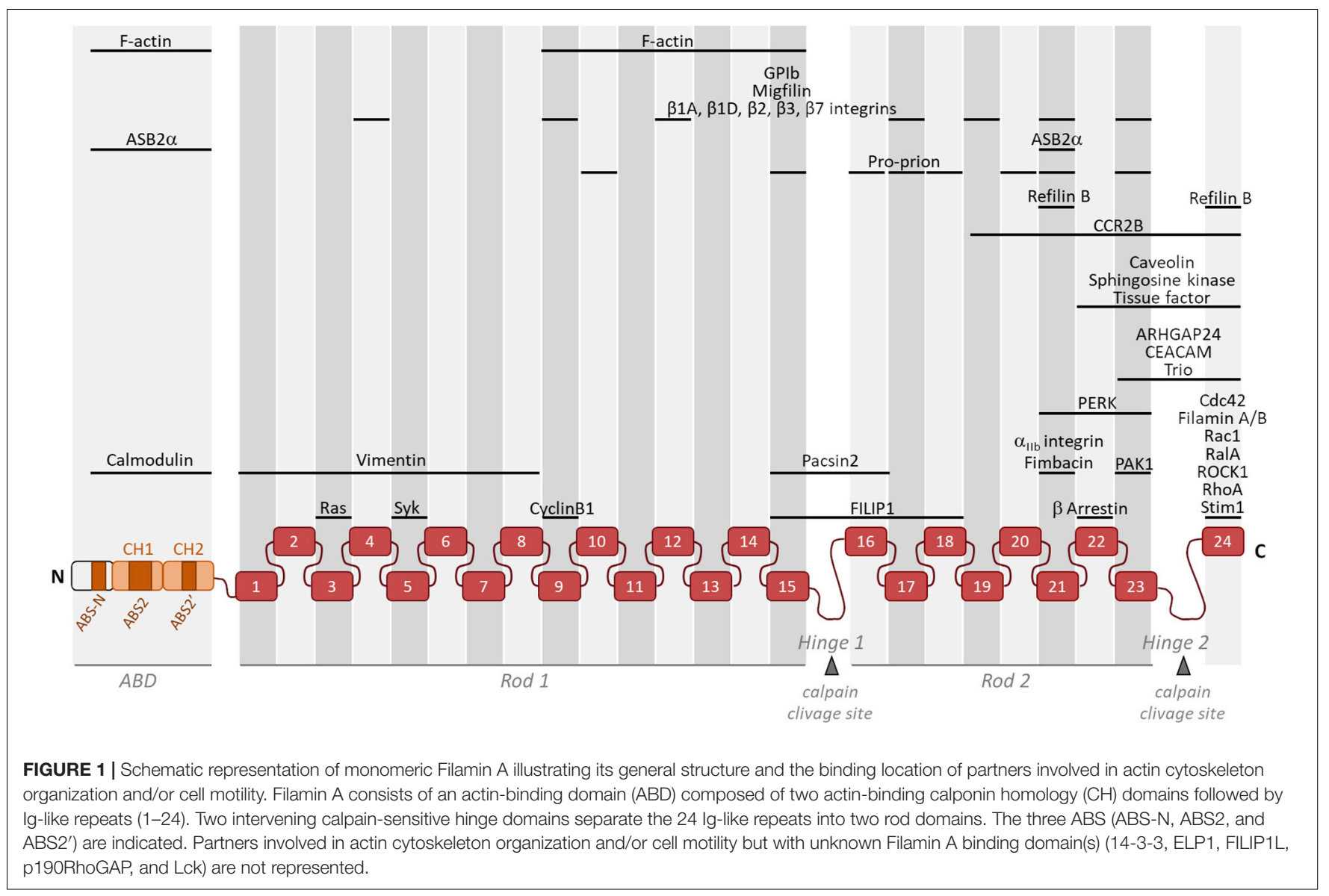

and cell to cell contacts and integrate external cues to the actin cytoskeleton and signaling pathways (Legate and Fassler, 2009; Humphries et al., 2019; Kechagia et al., 2019). Interactions between integrins and their extracellular ligands are tightly regulated thanks to integrin activators and integrin inhibitors. Importantly, switching integrins between inactive and active conformations is crucial for integrin functions (Bouvard et al., 2013). Integrin activation has largely been documented (Kim et al., 2011; Sun et al., 2019). This process is regulated via either extracellular ligands (outside-in activation) or intracellular binding partners (inside-out activation). Integrininactivating proteins such as integrin cytoplasmic domainassociated protein 1 (ICAP1), SHARPIN (SHANK-associated $\mathrm{RH}$ domain-interacting protein) and filamins are required for integrin inactivation in different settings (Calderwood et al., 2001; Bouvard et al., 2003; Rantala et al., 2011). The physiological relevance of integrin-inactivating proteins is crucial for integrin function as exemplified by the phenotypes of mice lacking integrin inactivators (Bouvard et al., 2013). Integrin inactivators either stabilize the inactive state of integrins or promote integrin deactivation during cyclical cell-adhesion processes such as migration. Indeed, a substantial proportion of cell surface integrins is in a resting state (Arjonen et al., 2012). Inactive integrins are in a closed conformation, in which the binding of both extracellular ligand and intracellular activators is repressed.
In human, there are several integrin $\beta$ subunits that bind filamins (Kiema et al., 2006; Ithychanda et al., 2009b).

Filamin A is a major gatekeeper to integrin activation. Since the discovery of Filamin A as a binding partner of the $\beta 2$ integrin subunit 25-years ago (Sharma et al., 1995) and the first evidence that increased Filamin A- $\beta 2$ integrin interactions restrict cell migration (Calderwood et al., 2001; Bouvard et al., 2003; Rantala et al., 2011), several modes of action of Filamin A as an integrin inactivator have been proposed. They depend on the identity of the integrin $\alpha$ and $\beta$ chains or could be specific to only a subset of integrin $\alpha \beta$ heterodimers. First, binding of Filamin A domains of subgroup $A$ to the $C$ terminus of the integrin $\beta$ tail $(\beta 1, \beta 2, \beta 3$, or $\beta 7)$ results in direct competition with talin binding by occupying an overlapping binding site (Kiema et al., 2006; Ithychanda et al., 2009b). Second, Filamin A forms a ternary complex engaging the cytoplasmic tails of both integrin $\alpha \mathrm{IIb}$ and $\beta 3$, thereby stabilizing the inner-membrane clasp and competing with talin recruitment to the $\beta$ subunit cytoplasmic tail by binding both the C-terminal and membrane-proximal regions of the $\beta 3$ tail (Liu et al., 2015). These two modes of action of Filamin A restrain the integrin in a resting state. Interestingly, domains within functionally important binding interfaces of both filamin repeats and integrin subunits have diverged in critical residues, indicating that filamin isoforms may bind and regulate integrin $\alpha \beta$ heterodimers differentially. Indeed, 
Kesner et al. (2010) described the substitution in the $\beta$ strand C of the filamin repeat 21, an ancestral Ser/Thr in Filamins B and $\mathrm{C}$ changed to an Ala at residue 2272 in Filamin A during the mammalian period. Furthermore, $\beta 1$ and $\beta 7$ integrins have ideally positioned hydrophobic amino acids to bind Filamin tighter than $\beta 2$ and $\beta 3$ integrins (Ithychanda et al., 2009b). Furthermore, some of the key residues in the $\alpha$ IIb subunit that are important for interaction with filamin via their side chains, are not conserved in all integrin $\alpha$ subunits, reinforcing the notion that filamins bind integrins differentially.

Because several Filamin A repeats can bind the cytoplasmic tails of $\beta$ integrins and have the ability to clasp $\alpha I I b$ and $\beta 3$ cytoplasmic tails, it seems plausible that they can bind simultaneously, and such interactions may promote clustering of inactive integrins (Ithychanda et al., 2009b; Liu et al., 2015). Although the biological significance of these Filamin A clutches remains to be establish, it is tempting to speculate that upon Filamin A removal, pre-clustered integrins would become engaged by multivalent ECM and thereby activated.

\section{MULTIPLE REGULATORY MECHANISMS CONTROLING FILAMIN A ACTIVITIES AND LEVELS}

Integrin activation can be achieved through the binding of proteins to Filamin A. Indeed, migfilin can bind Filamin A with a high affinity, uncoupling the Filamin A-integrin link, sequestering Filamin A away from the $\beta$ integrin cytoplasmic tail and thus counteracting Filamin A-mediated integrin inactivation (Lad et al., 2008; Ithychanda et al., 2009a; Das et al., 2011). This allows the binding of integrin activators, talin and kindlins, to the $\beta$ integrin cytoplasmic tail, leading to inside-out integrin activation (Tadokoro et al., 2003; Tu et al., 2003; Kiema et al., 2006; Wegener et al., 2007; Moser et al., 2008). Internally generated and externally imposed mechanical forces can also regulate Filamin A interaction with partners by triggering conformational changes that expose otherwise masked partnerbinding site, thereby leading to integrin activation (Ehrlicher et al., 2011; Nakamura et al., 2014). Although evidence for the mechanosensing function of Filamin A in Drosophila oogenesis has been provided, its precise role in cell differentiation and morphogenesis in mammals is still lacking (Razinia et al., 2012; Huelsmann et al., 2016). Filamin A is also regulated by phosphorylation. Several kinases such as protein kinase C (Kawamoto and Hidaka, 1984), ribosomal S6 kinase (Ohta and Hartwig, 1996; Woo et al., 2004), p21-activated kinase 1 (PAK1) (Vadlamudi et al., 2002; Hammer et al., 2013), the cyclic adenosine monophosphate (cAMP)-dependent protein kinase A (Jay et al., 2004), Akt (Li et al., 2015), mTOR2 (Chantaravisoot et al., 2015; Sato et al., 2016) and the serine/threonine kinase Ndr2 (Waldt et al., 2018) phosphorylate Filamin A on serine 2152. This phosphorylation event positively regulates cell migration (Woo et al., 2004; Hammer et al., 2013; Li et al., 2015; Sato et al., 2016). Activation of receptor tyrosine kinases was shown to trigger cell rounding and integrin inactivation via increased Filamin A phosphorylation
(Vial and McKeown-Longo, 2012; Mai et al., 2014). In addition, G Protein-Coupled Receptors that directly bind Filamin A can also promote Filamin A phosphorylation (Tirupula et al., 2015). Filamin A phosphorylation by the cAMP-dependent protein kinase protects Filamin A against proteolysis by calpains (Chen and Stracher, 1989). Phosphorylation of $\beta 2$ integrins impairs Filamin A binding, allowing the binding of the 14-3-3 protein to the $\beta 2$ subunit and adhesion of Jurkat $\mathrm{T}$ cells to ICAM-1 (Takala et al., 2008).

Tuning the cellular concentration of Filamin A represents another level of regulation expected to impact integrin activation, although this has not been formally demonstrated yet (Figure 2). Filamins are regulated by proteolysis, which provides an irreversible regulatory mechanism for processes requiring Filamin removal. Filamin A is cleaved by calpain and caspase at the two hinge regions, producing a $170 \mathrm{kDa}$ protein encompassing the ABD and Filamin A repeats 1 to 15 and a $110 \mathrm{kDa}$ protein that is further cleaved to generate a $90 \mathrm{kDa}$ fragment containing repeats 16 to 23 (Figure 1) (Gorlin et al., 1990; Browne et al., 2000). Filamins A and B are also regulated by proteasomal degradation which represents a fast, reversible, localized and selective regulatory mechanism that allows cells to acutely adapt or fine-tune cellular processes. Surprisingly, only few proteins linked to cytoskeleton dynamics, cell adhesion and migration have been shown to be regulated by this proteolysis pathway in non-muscle cells (Schaefer et al., 2012). Of interest, control of the cellular concentration of Filamins A through ubiquitin-mediated protein degradation represents a seminal example of proteasomal degradation of an actin-binding and crosslinking protein. Using several molecular and cellular biology approaches, we and others demonstrated that the ASB2 $\alpha$ E3 ubiquitin ligase (E3) triggers ubiquitylation and proteasomal degradation of Filamins A and B (Heuze et al., 2008; Burande et al., 2009; Lamsoul et al., 2013; Razinia et al., 2013; Sakane et al., 2013; Spinner et al., 2015; Metais et al., 2018). ASB2 $\alpha$ is the specificity subunit of a multimeric E3 of the Cullin 5-RING Ligase family involved in the recruitment of proteins to be ubiquitylated (Lamsoul et al., 2016). By degrading Filamins A and B, ASB2 $\alpha$ regulates cell spreading, adhesion and cell migration (Heuze et al., 2008; Baldassarre et al., 2009; Lamsoul et al., 2011, 2013; Spinner et al., 2015). Furthermore, our recent results support a model of cardiac cell differentiation that relies on a key role for $\mathrm{ASB} 2 \alpha$ in remodeling the actin cytoskeleton through induceddegradation of Filamin A (Metais et al., 2018). Indeed, the timely controlled removal of Filamin A ensures critical functions in differentiating cardiac muscle cells suggesting that Filamin A degradation is necessary to modify the actin cytoskeleton organization and properties in order to build the sarcomere, and thus for heartbeats. In addition, the Filamin A interacting protein (FILIP) interacts with Filamin A and induces its degradation with impacts on the mode of neuron migration (Nagano et al., 2004; Sato and Nagano, 2005). More recently, Filamin A expression was shown to be regulated by a microRNA ( $\mathrm{miR}$ ) and a circular RNA (circRNA). Indeed, miR-486-3p can bind Filamin A 3'UTR thereby reducing Filamin A expression while circFLNA sponges miR-486-3p resulting in increased Filamin A expression (Wang et al., 2019). Important questions remain: Does Filamin A 


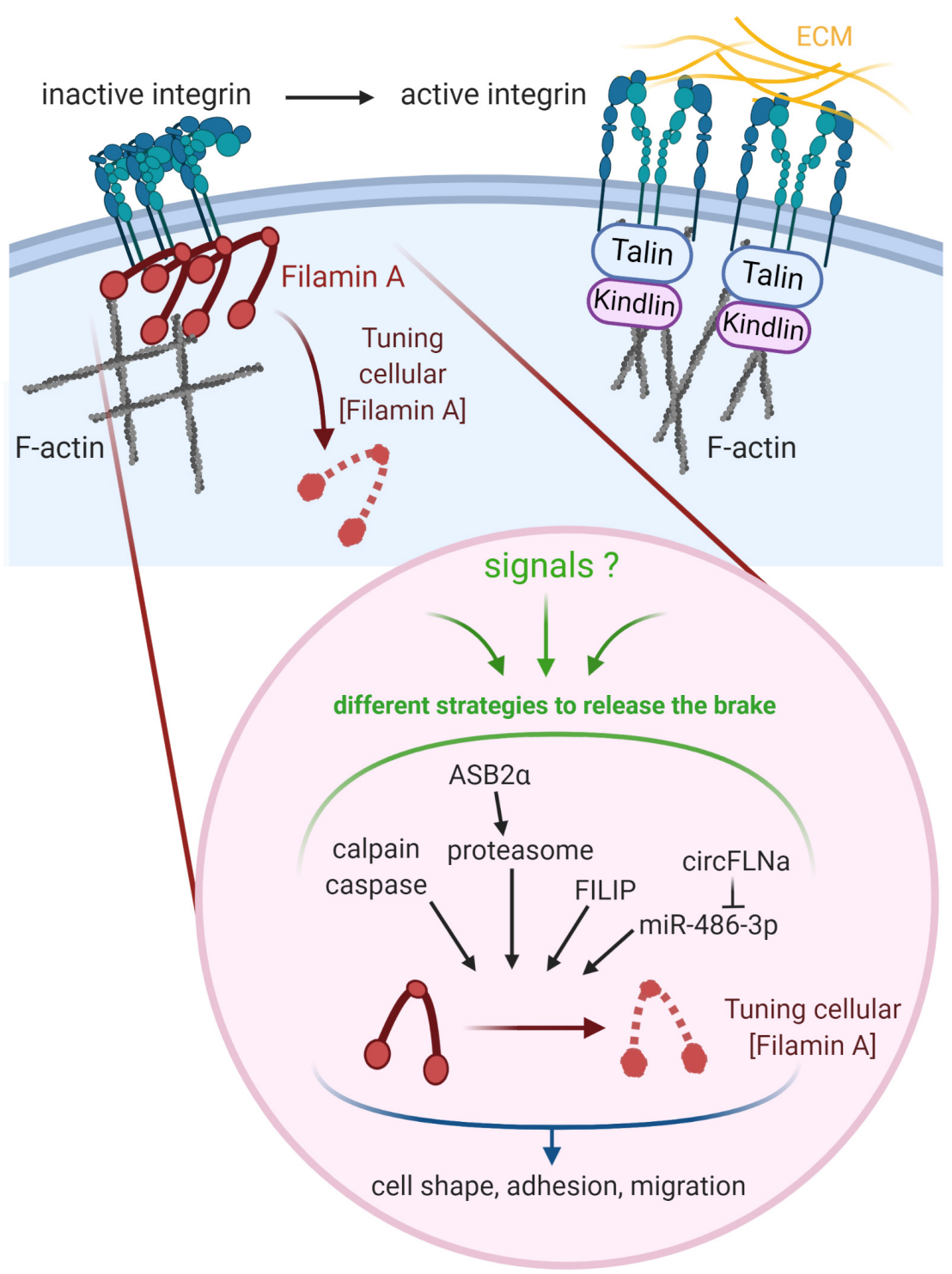

FIGURE 2 | Tuning the cellular concentration of Filamin A represents a pivotal mechanism to regulate integrin-dependent adhesion and migration. Regulation of integrins involves both integrin inhibitors (e.g., Filamin A) and integrin activators (e.g., Talin, Kindlin). Filamin A protein is regulated through cleavages by calpain and caspase, ASB2 $\alpha$-mediated degradation by the proteasome, and interaction with FILIP. Filamin A mRNA is down-regulated by miR-486-3p which is itself sponged by circFLNA. Created with BioRender.com.

degradation directly translate into increased integrin activation? What is the biological relevance of variable Filamin A levels in different cell subtypes or at discrete stages of cell differentiation? Why cells have evolved so many different mechanisms to regulate Filamin A activity and to up-regulate or down-regulate Filamin A concentration?

\section{FILAMIN A IN CELL ADHESION AND MIGRATION}

The first evidence for a role of Filamin A in cell motility was provided in 1992 (Cunningham et al., 1992). Indeed, at the cellular level, Filamin A deficiency in a human melanoma cell line promotes plasma membrane blebbing and causes loss of motility. The role of Filamin A in migration was further supported by the finding that nonsense mutations in the Filamin A gene are associated with the neuronal migration disorder periventricular heterotopia (Fox et al., 1998). However, the role of Filamin A in cell motility is more complex. By providing a physical link between integrins and the actin cytoskeleton and by negatively regulating integrins, Filamin A exerts key roles in regulating positively or negatively cell adhesion and migration according to cell types and/or conditions. Furthermore, Filamin A binding partners may vary according to cell types and/or in response to microenvironment 
cues such as extracellular matrix components, chemokines or shear flow. This is likely to influence cell adhesion and migration. While the loss of Filamins A or B alone has no effect on cell motility, loss of both filamins following knockdown/knockout or ASB2 $\alpha$-mediated degradation have highlighted the role of filamins in different aspects of cell motility (Heuze et al., 2008; Baldassarre et al., 2009; Lynch et al., 2011; Lamsoul et al., 2013; Spinner et al., 2015). It is tempting to speculate that the functions of Filamin $\mathrm{A}$ in many cell types may have been missed in assays using Filamin A single knockout/knockdown cells because of compensation by Filamin B (Sheen et al., 2002; Baldassarre et al., 2009). Filamin-depleted cells exhibit impaired cell spreading (Heuze et al., 2008; Kim et al., 2008; Baldassarre et al., 2009; Lynch et al., 2011). In addition, increased adhesion of Filamin A-depleted neutrophils has been described (Sun et al., 2013). Furthermore, Filamin A knockdown or ASB $2 \alpha$-mediated Filamin A degradation enhances adhesion of myeloid leukemia cells to fibronectin (Lamsoul et al., 2011). In contrast, Roth et al. found that Filamin A was dispensable for adhesion of differentiated HL-60 cells (Roth et al., 2017). However, Filamin A depleted primary murine neutrophils display increased spreading on and higher adhesion in shear-free conditions to $\beta 2$ integrin ligands, indicating that Filamin $\mathrm{A}$ is a negative regulator of $\beta 2$ integrin adhesion in neutrophils (Uotila et al., 2017). Although Filamin A negatively regulates $\beta 2$ integrin adhesion in Jurkat $\mathrm{T}$ cells, its absence leads to a reduction of primary $\mathrm{T}$ cell adhesion to integrin ligands under conditions of shear flow and to a reduced trafficking into lymph nodes and sites of inflammation (Moser et al., 2009; Savinko et al., 2018). Interestingly, Filamin A and vimentin can cooperate to regulate integrin-mediated cell spreading and cell adhesion (Kim et al., 2010a,b).

Filamins A and B depleted cells exhibit impaired initiation of migration of fibrosarcoma HT1080 cells (Baldassarre et al., 2009). Filamin A silencing increases cell adhesion and decreased migration of the bronchial carcinoid H727 cells (Vitali et al., 2017). In contrast, silencing of Filamin A inhibits Snail-induced adhesion and increases migration of colon adenocarcinoma HT29 cells (Wieczorek et al., 2017). In accordance with these results, Filamin $\mathrm{A}$ is required to mediate SST2 effects on adhesion and migration of the pancreatic endocrine QGP1 cells (Vitali et al., 2016). Filamin A also positively regulates directional migration of bone osteosarcoma U-2 OS cells and mouse embryonic fibroblasts by suppressing $\operatorname{Rac} 1$ activity downstream of $\beta 1$ integrins (Jacquemet et al., 2013). Knockdown of Filamins A and B in fibrosarcoma cells was also shown to augment matrix metalloproteinase activity increasing their invasive potential (Baldassarre et al., 2012). These results are in agreement with the fact that ASB2 $\alpha$ regulates immature dendritic cell migration by promoting extracellular matrix proteolysis (Lamsoul et al., 2013). Conversely, Filamin A stabilizes podosomes in macrophages and is required for their mesenchymal but not for their amoeboid migration (Guiet et al., 2012). In addition, in the absence of Filamin A, macrophages display impaired migration associated with reduced atherosclerosis in mice (Bandaru et al., 2019). Several evidences indicate that Filamin A regulates the intracellular trafficking of $\beta 1$ integrins (Meyer et al., 1998; Kim et al., 2010b). This is likely to affect $\beta 1$ integrin-dependent processes. On the basis of these scattered observations, it is clear that we still miss today a unified view of the roles of Filamin A in cell adhesion and migration.

\section{CONCLUDING REMARKS}

As reviewed here, the timely proteolysis and/or removal of Filamin A have emerged as pivotal mechanisms to regulate its cellular concentration and integrin-dependent adhesion and migration. When integrating the knowledge gained about the function of Filamin A beyond its integrin regulation role, one is tempted to speculate that this key protein at the interface between multiple receptors, signaling pathways and the actin cytoskeleton exerts different and specific cellular functions in response to a wide-range of environmental cues. As exemplified by the wide spectrum of developmental malformations and diseases caused by mutations in its gene, Filamin A indeed stands out as a major molecular player in different biological processes. In this context, it will be particularly interesting to further investigate how the multiple mechanisms able to adjust Filamin A concentration and activity contribute to its function in different cellular and physiological settings.

\section{AUTHOR CONTRIBUTIONS}

All authors contributed to both the review conceptualization and the writing process.

\section{FUNDING}

Research in our lab related to the subject of this review was supported by INSERM, CNRS, University of Toulouse and grants from the Fondation ARC pour la Recherche sur le Cancer, the Comité Midi-Pyrénées de la Ligue contre le Cancer and Sanofi iAwards Europe (to PGL) and the CNRS IRP program (grant "SysTact" to LD).

\section{ACKNOWLEDGMENTS}

The authors apologize to their colleagues whose work could not be cited due to space constraints. 


\section{REFERENCES}

Arjonen, A., Alanko, J., Veltel, S., and Ivaska, J. (2012). Distinct recycling of active and inactive betal integrins. Traffic 13, 610-625. doi: 10.1111/j.1600-0854. 2012.01327.x

Baldassarre, M., Razinia, Z., Brahme, N. N., Buccione, R., and Calderwood, D. A. (2012). Filamin A controls matrix metalloproteinase activity and regulates cell invasion in human fibrosarcoma cells. J. Cell Sci 125, 3858-3869. doi: 10.1242/ jcs. 104018

Baldassarre, M., Razinia, Z., Burande, C. F., Lamsoul, I., Lutz, P. G., and Calderwood, D. A. (2009). Filamins regulate cell spreading and initiation of cell migration. PLoS One 4:e7830. doi: 10.1371/journal.pone.0007830

Bandaru, S., Ala, C., Salimi, R., Akula, M. K., Ekstrand, M., Devarakonda, S., et al. (2019). Targeting filamin a reduces macrophage activity and atherosclerosis. Circulation 140, 67-79. doi: 10.1161/circulationaha.119.039697

Bellanger, J. M., Astier, C., Sardet, C., Ohta, Y., Stossel, T. P., and Debant, A. (2000). The Rac1- and RhoG-specific GEF domain of Trio targets filamin to remodel cytoskeletal actin. Nat. Cell Biol. 2, 888-892. doi: 10.1038/35046533

Berrou, E., Adam, F., Lebret, M., Planche, V., Fergelot, P., Issertial, O., et al. (2017). Gain-of-function mutation in filamin a potentiates platelet integrin alphaIIbbeta3 activation. Arterioscler. Thromb. Vasc. Biol. 37, 1087-1097. doi: 10.1161/atvbaha.117.309337

Bouvard, D., Pouwels, J., De Franceschi, N., and Ivaska, J. (2013). Integrin inactivators: balancing cellular functions in vitro and in vivo. Nat. Rev. Mol. Cell Biol. 14, 430-442. doi: 10.1038/nrm3599

Bouvard, D., Vignoud, L., Dupe-Manet, S., Abed, N., Fournier, H. N., VincentMonegat, C., et al. (2003). Disruption of focal adhesions by integrin cytoplasmic domain-associated protein-1 alpha. J. Biol. Chem. 278, 6567-6574. doi: 10.1074/ jbc.m211258200

Browne, K. A., Johnstone, R. W., Jans, D. A., and Trapani, J. A. (2000). Filamin (280-kDa actin-binding protein) is a caspase substrate and is also cleaved directly by the cytotoxic T lymphocyte protease granzyme B during apoptosis. J. Biol. Chem. 275, 39262-39266. doi: 10.1074/jbc.c000622200

Burande, C. F., Heuze, M. L., Lamsoul, I., Monsarrat, B., Uttenweiler-Joseph, S., and Lutz, P. G. (2009). A label-free quantitative proteomics strategy to identify E3 ubiquitin ligase substrates targeted to proteasome degradation. Mol. Cell Proteomics 8, 1719-1727. doi: 10.1074/mcp.m800410-mcp200

Calderwood, D. A., Huttenlocher, A., Kiosses, W. B., Rose, D. M., Woodside, D. G., Schwartz, M. A., et al. (2001). Increased filamin binding to beta-integrin cytoplasmic domains inhibits cell migration. Nat. Cell Biol. 3, 1060-1068. doi: 10.1038/ncb1201-1060

Chantaravisoot, N., Wongkongkathep, P., Loo, J. A., Mischel, P. S., and Tamanoi, F. (2015). Significance of filamin A in mTORC2 function in glioblastoma. Mol. Cancer 14:127.

Chen, M., and Stracher, A. (1989). In situ phosphorylation of platelet actin-binding protein by cAMP-dependent protein kinase stabilizes it against proteolysis by calpain. J. Biol. Chem. 264, 14282-14289.

Clark, A. R., Sawyer, G. M., Robertson, S. P., and Sutherland-Smith, A. J. (2009). Skeletal dysplasias due to filamin A mutations result from a gain-of-function mechanism distinct from allelic neurological disorders. Hum. Mol. Genet. 18, 4791-4800. doi: 10.1093/hmg/ddp442

Cunningham, C. C., Gorlin, J. B., Kwiatkowski, D. J., Hartwig, J. H., Janmey, P. A., Byers, H. R., et al. (1992). Actin-binding protein requirement for cortical stability and efficient locomotion. Science 255, 325-327. doi: 10.1126/science. 1549777

Dalkilic, I., Schienda, J., Thompson, T. G., and Kunkel, L. M. (2006). Loss of FilaminC (FLNc) results in severe defects in myogenesis and myotube structure. Mol. Cell Biol. 26, 6522-6534. doi: 10.1128/mcb.00243-06

Das, M., Ithychanda, S. S., Qin, J., and Plow, E. F. (2011). Migfilin and filamin as regulators of integrin activation in endothelial cells and neutrophils. PLoS One 6:e26355. doi: 10.1371/journal.pone.0026355

Donada, A., Balayn, N., Sliwa, D., Lordier, L., Ceglia, V., Baschieri, F., et al. (2019). Disrupted filamin A/alphaIIbbeta3 interaction induces macrothrombocytopenia by increasing RhoA activity. Blood 133, 1778-1788. doi: 10.1182/blood-2018-07-861427

Duff, R. M., Tay, V., Hackman, P., Ravenscroft, G., McLean, C., Kennedy, P., et al. (2011). Mutations in the $\mathrm{N}$-terminal actin-binding domain of filamin $\mathrm{C}$ cause a distal myopathy. Am. J. Hum. Genet. 88, 729-740. doi: 10.1016/j.ajhg.2011. 04.021

Ehrlicher, A. J., Nakamura, F., Hartwig, J. H., Weitz, D. A., and Stossel, T. P. (2011) Mechanical strain in actin networks regulates FilGAP and integrin binding to filamin A. Nature 478, 260-263. doi: 10.1038/nature10430

Esue, O., Tseng, Y., and Wirtz, D. (2009). Alpha-actinin and filamin cooperatively enhance the stiffness of actin filament networks. PLoS One 4:e4411. doi: 10. 1371/journal.pone.0004411

Farrington-Rock, C., Firestein, M. H., Bicknell, L. S., Superti-Furga, A., Bacino, C. A., Cormier-Daire, V., et al. (2006). Mutations in two regions of FLNB result in atelosteogenesis I and III. Hum. Mutat. 27, 705-710. doi: 10.1002/humu. 20348

Farrington-Rock, C., Kirilova, V., Dillard-Telm, L., Borowsky, A. D., Chalk, S., Rock, M. J., et al. (2008). Disruption of the Flnb gene in mice phenocopies the human disease spondylocarpotarsal synostosis syndrome. Hum. Mol. Genet. 17, 631-641. doi: 10.1093/hmg/ddm188

Feng, Y., Chen, M. H., Moskowitz, I. P., Mendonza, A. M., Vidali, L., Nakamura, F., et al. (2006). Filamin A (FLNA) is required for cell-cell contact in vascular development and cardiac morphogenesis. Proc. Natl. Acad. Sci. U.S.A. 103, 19836-19841. doi: 10.1073/pnas.0609628104

Fox, J. W., Lamperti, Eksioglu, Y. Z., Hong, S. E., Feng, Y., Graham, D. A., et al. (1998). Mutations in filamin 1 prevent migration of cerebral cortical neurons in human periventricular heterotopia. Neuron 21, 1315-1325. doi: 10.1016/s08966273(00)80651-0

Gardel, M. L., Nakamura, F., Hartwig, J. H., Crocker, J. C., Stossel, T. P., and Weitz, D. A. (2006). Prestressed F-actin networks cross-linked by hinged filamins replicate mechanical properties of cells. Proc. Natl. Acad. Sci. U.S.A. 103, 1762-1767. doi: 10.1073/pnas.0504777103

Goetsch, S. C., Martin, C. M., Embree, L. J., and Garry, D. J. (2005). Myogenic progenitor cells express filamin $\mathrm{C}$ in developing and regenerating skeletal muscle. Stem Cells Dev. 14, 181-187. doi: 10.1089/scd.2005.14.181

Gorlin, J. B., Yamin, R., Egan, S., Stewart, M., Stossel, T. P., Kwiatkowski, D. J., et al. (1990). Human endothelial actin-binding protein (ABP-280, nonmuscle filamin): a molecular leaf spring. J. Cell Biol. 111, 1089-1105. doi: 10.1083/jcb. 111.3.1089

Guiet, R., Verollet, C., Lamsoul, I., Cougoule, C., Poincloux, R., Labrousse, A., et al. (2012). Macrophage mesenchymal migration requires podosome stabilization by filamin A. J. Biol. Chem. 287, 13051-13062. doi: 10.1074/jbc.m111.307124

Hammer, A., Rider, L., Oladimeji, P., Cook, L., Li, Q., Mattingly, R. R., et al. (2013). Tyrosyl phosphorylated PAK1 regulates breast cancer cell motility in response to prolactin through filamin A. Mol. Endocrinol. 27, 455-465. doi: 10.1210/me.2012-1291

Hart, A. W., Morgan, J. E., Schneider, J., West, K., McKie, L., Bhattacharya, S. et al. (2006). Cardiac malformations and midline skeletal defects in mice lacking filamin A. Hum. Mol. Genet. 15, 2457-2467. doi: 10.1093/hmg/ddl168

Heikkinen, O. K., Ruskamo, S., Konarev, P. V., Svergun, D. I., Iivanainen, T., Heikkinen, S. M., et al. (2009). Atomic structures of two novel immunoglobulinlike domain pairs in the actin cross-linking protein filamin. J. Biol. Chem. 284, 25450-25458. doi: 10.1074/jbc.m109.019661

Heuze, M. L., Lamsoul, I., Baldassarre, M., Lad, Y., Leveque, S., Razinia, Z., et al. (2008). ASB2 targets filamins A and B to proteasomal degradation. Blood 112, 5130-5140. doi: 10.1182/blood-2007-12-128744

Huelsmann, S., Rintanen, N., Sethi, R., Brown, N. H., and Ylanne, J. (2016). Evidence for the mechanosensor function of filamin in tissue development. Sci. Rep. 6:32798.

Humphries, J. D., Chastney, M. R., Askari, J. A., and Humphries, M. J. (2019). Signal transduction via integrin adhesion complexes. Curr. Opin. Cell Biol. 56, 14-21. doi: 10.1016/j.ceb.2018.08.004

Ithychanda, S. S., Das, M., Ma, Y. Q., Ding, K., Wang, X., Gupta, S., et al. (2009a). Migfilin, a molecular switch in regulation of integrin activation. J. Biol. Chem. 284, 4713-4722. doi: 10.1074/jbc.m807719200

Ithychanda, S. S., Hsu, D., Li, H., Yan, L., Liu, D., Das, M., et al. (2009b). Identification and characterization of multiple similar ligand-binding repeats in filamin: implication on filamin-mediated receptor clustering and cross-talk. J. Biol. Chem. 284, 35113-35121. doi: 10.1074/jbc.m109.060954

Iwamoto, D. V., Huehn, A., Simon, B., Huet-Calderwood, C., Baldassarre, M., Sindelar, C. V., et al. (2018). Structural basis of the filamin A actin-binding 
domain interaction with F-actin. Nat. Struct. Mol. Biol. 25, 918-927. doi: 10.1038/s41594-018-0128-3

Jacquemet, G., Morgan, M. R., Byron, A., Humphries, J. D., Choi, C. K., Chen, C. S., et al. (2013). Racl is deactivated at integrin activation sites through an IQGAP1-filamin-A-RacGAP1 pathway. J. Cell Sci. 126, 4121-4135. doi: $10.1242 /$ jcs. 121988

Jay, D., Garcia, E. J., and de la Luz Ibarra, M. (2004). In situ determination of a PKA phosphorylation site in the C-terminal region of filamin. Mol. Cell. Biochem. 260, 49-53. doi: 10.1023/b:mcbi.0000026052.76418.55

Kasza, K. E., Koenderink, G. H., Lin, Y. C., Broedersz, C. P., Messner, W., Nakamura, F., et al. (2009). Nonlinear elasticity of stiff biopolymers connected by flexible linkers. Phys. Rev. E Stat. Nonlin. Soft. Matter. Phys. 79:041928.

Kawamoto, S., and Hidaka, H. (1984). Ca2+-activated, phospholipid-dependent protein kinase catalyzes the phosphorylation of actin-binding proteins. Biochem. Biophys. Res. Commun. 118, 736-742. doi: 10.1016/0006-291x(84) 91456-6

Kechagia, J. Z., Ivaska, J., and Roca-Cusachs, P. (2019). Integrins as biomechanical sensors of the microenvironment. Nat. Rev. Mol. Cell Biol. 20, 457-473. doi: 10.1038/s41580-019-0134-2

Kesner, B. A., Milgram, S. L., Temple, B. R., and Dokholyan, N. V. (2010). Isoform divergence of the filamin family of proteins. Mol. Biol. Evol. 27, 283-295. doi: 10.1093/molbev/msp236

Kiema, T., Lad, Y., Jiang, P., Oxley, C. L., Baldassarre, M., Wegener, K. L., et al. (2006). The molecular basis of filamin binding to integrins and competition with talin. Mol. Cell 21, 337-347. doi: 10.1016/j.molcel.2006.01.011

Kim, C., Ye, F., and Ginsberg, M. H. (2011). Regulation of integrin activation. Annu. Rev. Cell Dev. Biol. 27, 321-345.

Kim, H., Nakamura, F., Lee, W., Hong, C., Perez-Sala, D., and McCulloch, C. A. (2010a). Regulation of cell adhesion to collagen via betal integrins is dependent on interactions of filamin A with vimentin and protein kinase $\mathrm{C}$ epsilon. Exp. Cell Res. 316, 1829-1844. doi: 10.1016/j.yexcr.2010.02.007

Kim, H., Nakamura, F., Lee, W., Shifrin, Y., Arora, P., and McCulloch, C. A. (2010b). Filamin A is required for vimentin-mediated cell adhesion and spreading. Am. J. Physiol. Cell Physiol. 298, C221-C236.

Kim, H., Sengupta, A., Glogauer, M., and McCulloch, C. A. (2008). Filamin A regulates cell spreading and survival via betal integrins. Exp. Cell Res. 314, 834-846. doi: 10.1016/j.yexcr.2007.11.022

Kircher, P., Hermanns, C., Nossek, M., Drexler, M. K., Grosse, R., Fischer, M., et al. (2015). Filamin A interacts with the coactivator MKL1 to promote the activity of the transcription factor SRF and cell migration. Sci. Signal. 8:ra112. doi: 10.1126/scisignal.aad2959

Krakow, D., Robertson, S. P., King, L. M., Morgan, T., Sebald, E. T., Bertolotto, C., et al. (2004). Mutations in the gene encoding filamin B disrupt vertebral segmentation, joint formation and skeletogenesis. Nat. Genet. 36, 405-410. doi: $10.1038 /$ ng1319

Kumar, A., Shutova, M. S., Tanaka, K., Iwamoto, D. V., Calderwood, D. A., Svitkina, T. M., et al. (2019). Filamin A mediates isotropic distribution of applied force across the actin network. J. Cell Biol. 218, 2481-2491. doi: 10.1083/jcb. 201901086

Lad, Y., Jiang, P., Ruskamo, S., Harburger, D. S., Ylanne, J., Campbell, I. D., et al. (2008). Structural basis of the migfilin-filamin interaction and competition with integrin beta tails. J. Biol. Chem. 283, 35154-35163. doi: 10.1074/jbc. m802592200

Lad, Y., Kiema, T., Jiang, P., Pentikainen, O. T., Coles, C. H., Campbell, I. D., et al. (2007). Structure of three tandem filamin domains reveals auto-inhibition of ligand binding. EMBO J. 26, 3993-4004. doi: 10.1038/sj.emboj.7601827

Lamsoul, I., Burande, C. F., Razinia, Z., Houles, T. C., Menoret, D., Baldassarre, M., et al. (2011). Functional and structural insights into ASB2 $\alpha$, a novel regulator of integrin-dependent adhesion of hematopoietic cells. J. Biol. Chem. 286, 30571-30581. doi: 10.1074/jbc.m111.220921

Lamsoul, I., Metais, A., Gouot, E., Heuze, M. L., Lennon-Dumenil, A. M., MoogLutz, C., et al. (2013). ASB2alpha regulates migration of immature dendritic cells. Blood 122, 533-541. doi: 10.1182/blood-2012-11-466649

Lamsoul, I., Uttenweiler-Joseph, S., Moog-Lutz, C., and Lutz, P. G. (2016). Cullin 5-RING E3 ubiquitin ligases, new therapeutic targets? Biochimie 122, 339-347. doi: 10.1016/j.biochi.2015.08.003
Legate, K. R., and Fassler, R. (2009). Mechanisms that regulate adaptor binding to beta-integrin cytoplasmic tails. J. Cell Sci. 122, 187-198. doi: 10.1242/jcs. 041624

Li, C., Yu, S., Nakamura, F., Pentikainen, O. T., Singh, N., Yin, S., et al. (2010). Pro-prion binds filamin A, facilitating its interaction with integrin betal, and contributes to melanomagenesis. J. Biol. Chem. 285, 30328-30339. doi: 10.1074/ jbc.m110.147413

Li, L., Lu, Y., Stemmer, P. M., and Chen, F. (2015). Filamin A phosphorylation by Akt promotes cell migration in response to arsenic. Oncotarget 6, 12009-12019. doi: 10.18632/oncotarget.3617

Light, S., Sagit, R., Ithychanda, S. S., Qin, J., and Elofsson, A. (2012). The evolution of filamin-a protein domain repeat perspective. J. Struct. Biol. 179, 289-298. doi: 10.1016/j.jsb.2012.02.010

Liu, J., Das, M., Yang, J., Ithychanda, S. S., Yakubenko, V. P., Plow, E. F., et al. (2015). Structural mechanism of integrin inactivation by filamin. Nat. Struct. Mol. Biol. 22, 383-389. doi: 10.1038/nsmb.2999

Loy, C. J., Sim, K. S., and Yong, E. L. (2003). Filamin-A fragment localizes to the nucleus to regulate androgen receptor and coactivator functions. Proc. Natl. Acad. Sci. U.S.A. 100, 4562-4567. doi: 10.1073/pnas.0736237100

Lu, J., Lian, G., Lenkinski, R., De Grand, A., Vaid, R. R., Bryce, T., et al. (2007). Filamin B mutations cause chondrocyte defects in skeletal development. Hum. Mol. Genet. 16, 1661-1675. doi: 10.1093/hmg/ddm114

Lynch, C. D., Gauthier, N. C., Biais, N., Lazar, A. M., Roca-Cusachs, P., Yu, C. H., et al. (2011). Filamin depletion blocks endoplasmic spreading and destabilizes force-bearing adhesions. Mol. Biol. Cell 22, 1263-1273. doi: 10.1091/mbc.e1008-0661

Mai, A., Muharram, G., Barrow-McGee, R., Baghirov, H., Rantala, J., Kermorgant, S., et al. (2014). Distinct c-Met activation mechanisms induce cell rounding or invasion through pathways involving integrins, RhoA and HIP1. J. Cell Sci. 127, 1938-1952. doi: $10.1242 /$ jcs. 140657

McGrath, M. J., Binge, L. C., Sriratana, A., Wang, H., Robinson, P. A., Pook, D., et al. (2013). Regulation of the transcriptional coactivator FHL2 licenses activation of the androgen receptor in castrate-resistant prostate cancer. Cancer Res. 73, 5066-5079. doi: 10.1158/0008-5472.can-12-4520

Metais, A., Lamsoul, I., Melet, A., Uttenweiler-Joseph, S., Poincloux, R., Stefanovic, S., et al. (2018). Asb2alpha-Filamin A axis is essential for actin cytoskeleton remodeling during heart development. Circ. Res. 122:e34.

Meyer, S. C., Sanan, D. A., and Fox, J. E. (1998). Role of actin-binding protein in insertion of adhesion receptors into the membrane. J. Biol. Chem. 273, 3013-3020. doi: 10.1074/jbc.273.5.3013

Moser, M., Bauer, M., Schmid, S., Ruppert, R., Schmidt, S., Sixt, M., et al. (2009). Kindlin-3 is required for beta2 integrin-mediated leukocyte adhesion to endothelial cells. Nat. Med. 15, 300-305. doi: 10.1038/nm.1921

Moser, M., Nieswandt, B., Ussar, S., Pozgajova, M., and Fassler, R. (2008). Kindlin3 is essential for integrin activation and platelet aggregation. Nat. Med. 14, 325-330. doi: $10.1038 / \mathrm{nm} 1722$

Nagano, T., Morikubo, S., and Sato, M. (2004). Filamin A and FILIP (Filamin A-Interacting Protein) regulate cell polarity and motility in neocortical subventricular and intermediate zones during radial migration. J. Neurosci. 24, 9648-9657. doi: 10.1523/jneurosci.2363-04.2004

Nakamura, F., Heikkinen, O., Pentikainen, O. T., Osborn, T. M., Kasza, K. E., Weitz, D. A., et al. (2009). Molecular basis of filamin A-FilGAP interaction and its impairment in congenital disorders associated with filamin A mutations. PLoS One 4:e4928. doi: 10.1371/journal.pone.0004928

Nakamura, F., Osborn, T. M., Hartemink, C. A., Hartwig, J. H., and Stossel, T. P. (2007). Structural basis of filamin A functions. J. Cell Biol. 179, 1011-1025. doi: $10.1083 /$ jcb. 200707073

Nakamura, F., Pudas, R., Heikkinen, O., Permi, P., Kilpelainen, I., Munday, A. D., et al. (2006). The structure of the GPIb-filamin A complex. Blood 107, 1925-1932. doi: 10.1182/blood-2005-10-3964

Nakamura, F., Song, M., Hartwig, J. H., and Stossel, T. P. (2014). Documentation and localization of force-mediated filamin A domain perturbations in moving cells. Nat. Commun. 5:4656.

Ohta, Y., and Hartwig, J. H. (1996). Phosphorylation of actin-binding protein 280 by growth factors is mediated by $\mathrm{p} 90$ ribosomal protein S6 kinase. J. Biol. Chem. 271, 11858-11864. doi: 10.1074/jbc.271.20.11858 
Ohta, Y., Hartwig, J. H., and Stossel, T. P. (2006). FilGAP, a Rho- and ROCKregulated GAP for Rac binds filamin A to control actin remodelling. Nat. Cell Biol. 8, 803-814. doi: 10.1038/ncb1437

Ohta, Y., Suzuki, N., Nakamura, S., Hartwig, J. H., and Stossel, T. P. (1999). The small GTPase RalA targets filamin to induce filopodia. Proc. Natl. Acad. Sci. U.S.A. 96, 2122-2128. doi: 10.1073/pnas.96.5.2122

Rantala, J. K., Pouwels, J., Pellinen, T., Veltel, S., Laasola, P., Mattila, E., et al. (2011). SHARPIN is an endogenous inhibitor of betal-integrin activation. Nat. Cell Biol. 13, 1315-1324. doi: 10.1038/ncb2340

Razinia, Z., Baldassarre, M., Bouaouina, M., Lamsoul, I., Lutz, P. G., and Calderwood, D. A. (2011). The E3 ubiquitin ligase specificity subunit ASB2alpha targets filamins for proteasomal degradation by interacting with the filamin actin-binding domain. J. Cell Sci. 124, 2631-2641. doi: 10.1242/jcs. 084343

Razinia, Z., Baldassarre, M., Cantelli, G., and Calderwood, D. A. (2013). ASB2alpha, an E3 ubiquitin ligase specificity subunit, regulates cell spreading and triggers proteasomal degradation of filamins by targeting the filamin calponin homology 1 domain. J. Biol. Chem. 288, 32093-30105. doi: 10.1074/ jbc.m113.496604

Razinia, Z., Makela, T., Ylanne, J., and Calderwood, D. A. (2012). Filamins in mechanosensing and signaling. Annu. Rev. Biophys. 41, 227-246. doi: 10.1146/ annurev-biophys-050511-102252

Robertson, S. P., Twigg, S. R., Sutherland-Smith, A. J., Biancalana, V., Gorlin, R. J., Horn, D., et al. (2003). Localized mutations in the gene encoding the cytoskeletal protein filamin A cause diverse malformations in humans. Nat. Genet. 33, 487-491. doi: 10.1038/ng1119

Roth, H., Samereier, M., Begandt, D., Pick, R., Salvermoser, M., Brechtefeld, D., et al. (2017). Filamin A promotes efficient migration and phagocytosis of neutrophil-like HL-60 cells. Eur. J. Cell Biol. 96, 553-566. doi: 10.1016/j.ejcb. 2017.05.004

Sakane, A., Alamir Mahmoud, Abdallah, A., Nakano, K., Honda, K., Kitamura, T., et al. (2013). Junctional Rab13-binding protein (JRAB) regulates cell spreading via filamins. Genes Cells 18, 810-822. doi: 10.1111/gtc.12078

Sasaki, A., Masuda, Y., Ohta, Y., Ikeda, K., and Watanabe, K. (2001). Filamin associates with Smads and regulates transforming growth factor-beta signaling. J. Biol. Chem. 276, 17871-17877. doi: 10.1074/jbc.m008422200

Sato, M., and Nagano, T. (2005). Involvement of filamin A and filamin A-interacting protein (FILIP) in controlling the start and cell shape of radially migrating cortical neurons. Anat. Sci. Int. 80, 19-29. doi: 10.1111/j.1447-073x. 2005.00101.x

Sato, T., Ishii, J., Ota, Y., Sasaki, E., Shibagaki, Y., and Hattori, S. (2016). Mammalian target of rapamycin (mTOR) complex 2 regulates filamin A-dependent focal adhesion dynamics and cell migration. Genes Cells 21, 579-593. doi: 10.1111/gtc.12366

Savinko, T., Guenther, C., Uotila, L. M., Llort Asens, M., Yao, S., Tojkander, S., et al. (2018). Filamin A is required for optimal $\mathrm{T}$ cell integrin-mediated force transmission, flow adhesion, and T cell trafficking. J. Immunol. 200, 3109-3116. doi: 10.4049/jimmunol.1700913

Savoy, R. M., Chen, L., Siddiqui, S., Melgoza, F. U., Durbin-Johnson, B., Drake, C., et al. (2015). Transcription of Nrdpl by the androgen receptor is regulated by nuclear filamin A in prostate cancer. Endocr. Relat. Cancer 22, 369-386. doi: 10.1530/erc-15-0021

Schaefer, A., Nethe, M., and Hordijk, P. L. (2012). Ubiquitin links to cytoskeletal dynamics, cell adhesion and migration. Biochem. J. 442, 13-25. doi: 10.1042/ bj20111815

Schmoller, K. M., Lieleg, O., and Bausch, A. R. (2009). Structural and viscoelastic properties of actin/filamin networks: cross-linked versus bundled networks. Biophys. J. 97, 83-89. doi: 10.1016/j.bpj.2009.04.040

Sharma, C. P., Ezzell, R. M., and Arnaout, M. A. (1995). Direct interaction of filamin (ABP-280) with the beta 2-integrin subunit CD18. J. Immunol. 154, 3461-3470.

Sheen, V. L., Feng, Y., Graham, D., Takafuta, T., Shapiro, S. S., and Walsh, C. A. (2002). Filamin A and Filamin B are co-expressed within neurons during periods of neuronal migration and can physically interact. Hum. Mol. Genet. 11, 2845-2854. doi: 10.1093/hmg/11.23.2845

Smith, L., Page, R. C., Xu, Z., Kohli, E., Litman, P., Nix, J. C., et al. (2010). Biochemical basis of the interaction between cystic fibrosis transmembrane conductance regulator and immunoglobulin-like repeats of filamin. J. Biol. Chem. 285, 17166-17176. doi: 10.1074/jbc.m109.080911
Spinner, C. A., Uttenweiler-Joseph, S., Metais, A., Stella, A., Burlet-Schiltz, O., Moog-Lutz, C., et al. (2015). Substrates of the ASB2alpha E3 ubiquitin ligase in dendritic cells. Sci. Rep. 5:16269.

Sun, C., Forster, C., Nakamura, F., and Glogauer, M. (2013). Filamin-A regulates neutrophil uropod retraction through RhoA during chemotaxis. PLoS One 8:e79009. doi: 10.1371/journal.pone.0079009

Sun, Z., Costell, M., and Fassler, R. (2019). Integrin activation by talin, kindlin and mechanical forces. Nat. Cell Biol. 21, 25-31. doi: 10.1038/s41556-018-0234-9

Tadokoro, S., Shattil, S. J., Eto, K., Tai, V., Liddington, R. C., de Pereda, J. M., et al. (2003). Talin binding to integrin beta tails: a final common step in integrin activation. Science 302, 103-106. doi: 10.1126/science.1086652

Takala, H., Nurminen, E., Nurmi, S. M., Aatonen, M., Strandin, T., Takatalo, M., et al. (2008). Beta2 integrin phosphorylation on Thr758 acts as a molecular switch to regulate 14-3-3 and filamin binding. Blood 112, 1853-1862. doi: 10.1182/blood-2007-12-127795

Tirupula, K. C., Ithychanda, S. S., Mohan, M. L., Naga Prasad, S. V., Qin, J., and Karnik, S. S. (2015). G protein-coupled receptors directly bind filamin A with high affinity and promote filamin phosphorylation. Biochemistry 54, 6673-6683. doi: 10.1021/acs.biochem.5b00975

Tseng, Y., An, K. M., Esue, O., and Wirtz, D. (2004). The bimodal role of filamin in controlling the architecture and mechanics of F-actin networks. J. Biol. Chem. 279, 1819-1826. doi: 10.1074/jbc.m306090200

Tu, Y., Wu, S., Shi, X., Chen, K., and Wu, C. (2003). Migfilin and Mig-2 link focal adhesions to filamin and the actin cytoskeleton and function in cell shape modulation. Cell 113, 37-47. doi: 10.1016/s0092-8674(03)00163-6

Ueda, K., Ohta, Y., and Hosoya, H. (2003). The carboxy-terminal pleckstrin homology domain of ROCK interacts with filamin-A. Biochem. Biophys. Res. Commun. 301, 886-890. doi: 10.1016/s0006-291x(03)00048-2

Uotila, L. M., Guenther, C., Savinko, T., Lehti, T. A., and Fagerholm, S. C. (2017). Filamin A regulates neutrophil adhesion, production of reactive oxygen species, and neutrophil extracellular trap release. J. Immunol. 199, 3644-3653. doi: 10.4049/jimmunol.1700087

Vadlamudi, R. K., Li, F., Adam, L., Nguyen, D., Ohta, Y., Stossel, T. P., et al. (2002). Filamin is essential in actin cytoskeletal assembly mediated by p21-activated kinase 1. Nat. Cell Biol. 4, 681-690. doi: 10.1038/ncb838

van der Flier, A., and Sonnenberg, A. (2001). Structural and functional aspects of filamins. Biochim. Biophys. Acta 1538, 99-117. doi: 10.1016/s0167-4889(01) 00072-6

van der Ven, P. F., Obermann, W. M., Lemke, B., Gautel, M., Weber, K., and Furst, D. O. (2000). Characterization of muscle filamin isoforms suggests a possible role of gamma-filamin/ABP-L in sarcomeric Z-disc formation. Cell Motil. Cytoskeleton 45, 149-162. doi: 10.1002/(sici)1097-0169(200002)45:2<149::aidcm6>3.0.co; $2-\mathrm{g}$

Velkova, A., Carvalho, M. A., Johnson, J. O., Tavtigian, S. V., and Monteiro, A. N. (2010). Identification of Filamin A as a BRCA1-interacting protein required for efficient DNA repair. Cell Cycle 9, 1421-1433. doi: 10.4161/cc.9.7.11256

Vial, D., and McKeown-Longo, P. J. (2012). Epidermal growth factor (EGF) regulates alpha5betal integrin activation state in human cancer cell lines through the p90RSK-dependent phosphorylation of filamin A. J. Biol. Chem. 287, 40371-40380. doi: 10.1074/jbc.m112.389577

Vitali, E., Boemi, I., Rosso, L., Cambiaghi, V., Novellis, P., Mantovani, G., et al. (2017). FLNA is implicated in pulmonary neuroendocrine tumors aggressiveness and progression. Oncotarget 8, 77330-77340. doi: 10.18632/ oncotarget. 20473

Vitali, E., Cambiaghi, V., Zerbi, A., Carnaghi, C., Colombo, P., Peverelli, E., et al. (2016). Filamin-A is required to mediate SST2 effects in pancreatic neuroendocrine tumours. Endocr. Relat. Cancer 23, 181-190. doi: 10.1530/erc15- 0358

Vorgerd, M., van der Ven, P. F., Bruchertseifer, V., Lowe, T., Kley, R. A., Schroder, R., et al. (2005). A mutation in the dimerization domain of filamin c causes a novel type of autosomal dominant myofibrillar myopathy. Am. J. Hum. Genet. 77, 297-304. doi: 10.1086/431959

Wade, E. M., Halliday, B. J., Jenkins, Z. A., O’Neill, A. C., and Robertson, S. P. (2020). The X-linked filaminopathies: synergistic insights from clinical and molecular analysis. Hum. Mutat. 41, 865-883. doi: 10.1002/humu.24002

Waldt, N., Seifert, A., Demiray, Y. E., Devroe, E., Turk, B. E., Reichardt, P., et al. (2018). Filamin A phosphorylation at serine 2152 by the serine/threonine kinase Ndr2 controls TCR-induced LFA-1 activation in T Cells. Front. Immunol. 9:2852. doi: 10.3389/fimmu.2018.02852 
Wang, L., and Nakamura, F. (2019a). Identification of Filamin A mechanobinding partner I: smoothelin specifically interacts with the Filamin A mechanosensitive domain 21. Biochemistry 58, 4726-4736. doi: 10.1021/acs.biochem.9b0 0100

Wang, J., and Nakamura, F. (2019b). Identification of Filamin A mechanobinding partner II: fimbacin is a novel actin cross-linking and Filamin A binding protein. Biochemistry 58, 4737-4743. doi: 10.1021/acs.biochem.9b00101

Wang, J. X., Liu, Y., Jia, X. J., Liu, S. X., Dong, J. H., Ren, X. M., et al. (2019). Upregulation of circFLNA contributes to laryngeal squamous cell carcinoma migration by circFLNA-miR-486-3p-FLNA axis. Cancer Cell Int. 19:196.

Wegener, K. L., Partridge, A. W., Han, J., Pickford, A. R., Liddington, R. C., Ginsberg, M. H., et al. (2007). Structural basis of integrin activation by talin. Cell 128, 171-182. doi: 10.1016/j.cell.2006.10.048

Wieczorek, K., Wiktorska, M., Sacewicz-Hofman, I., Boncela, J., Lewinski, A., Kowalska, M. A., et al. (2017). Filamin A upregulation correlates with Snailinduced epithelial to mesenchymal transition (EMT) and cell adhesion but its inhibition increases the migration of colon adenocarcinoma HT29 cells. Exp. Cell Res. 359, 163-170. doi: 10.1016/j.yexcr.2017.07.035

Woo, M. S., Ohta, Y., Rabinovitz, I., Stossel, T. P., and Blenis, J. (2004). Ribosomal S6 kinase (RSK) regulates phosphorylation of filamin A on an important regulatory site. Mol. Cell Biol. 24, 3025-3035. doi: 10.1128/mcb.24.7.3025-3035. 2004

Yamak, A., Hu, D., Mittal, N., Buikema, J. W., Ditta, S., Lutz, P. G., et al. (2020). Loss of Asb2 impairs cardiomyocyte differentiation and leads to congenital double outlet right ventricle. iScience 23:100959. doi: 10.1016/j.isci.2020.10 0959
Yoshida, N., Ogata, T., Tanabe, K., Li, S., Nakazato, M., Kohu, K., et al. (2005). Filamin A-bound PEBP2beta/CBFbeta is retained in the cytoplasm and prevented from functioning as a partner of the Runx1 transcription factor. Mol. Cell Biol. 25, 1003-1012. doi: 10.1128/mcb.25.3.1003-1012.2005

Yue, J., Wang, Q., Lu, H., Brenneman, M., Fan, F., and Shen, Z. (2009). The cytoskeleton protein filamin-A is required for an efficient recombinational DNA double strand break repair. Cancer Res. 69, 7978-7985. doi: 10.1158/ 0008-5472.can-09-2177

Zhou, X., Tian, F., Sandzen, J., Cao, R., Flaberg, E., Szekely, L., et al. (2007). Filamin B deficiency in mice results in skeletal malformations and impaired microvascular development. Proc. Natl. Acad. Sci. U.S.A. 104, 3919-3924. doi: 10.1073/pnas.0608360104

Zhou, Y., Chen, Z., Zhang, L., Zhu, M., Tan, C., Zhou, X., et al. (2020). Loss of Filamin $\mathrm{C}$ is catastrophic for heart function. Circulation 141, 869-871. doi: 10.1161/circulationaha.119.044061

Conflict of Interest: The authors declare that the research was conducted in the absence of any commercial or financial relationships that could be construed as a potential conflict of interest.

Copyright (C) 2020 Lamsoul, Dupré and Lutz. This is an open-access article distributed under the terms of the Creative Commons Attribution License (CC BY). The use, distribution or reproduction in other forums is permitted, provided the original author(s) and the copyright owner(s) are credited and that the original publication in this journal is cited, in accordance with accepted academic practice. No use, distribution or reproduction is permitted which does not comply with these terms. 